\title{
Verdreckte Luft - der ungerechte Killer
}

\section{Die Ozon- und Feinstaubexposition erhöht dosisab-} hängig die Mortalität, wie eine US-Megastudie zeigt. Besonders betroffen sind sozial Benachteiligte.

_ Der Zusammenhang zwischen einer verminderten Lebenserwartung und der Exposition gegenüber Feinstaubpartikeln mit einer Größe $<25 \mu \mathrm{m}$ (PM25) und Ozon ist bekannt. Die meisten Daten stammen bisher aus Städten und aus Kollektiven mit wohlhabender Bevölkerung. Eine neue Untersuchung zieht nun die Sterbedaten aus Medicare-Registern heran. Bei Medicare sind 96\% aller Menschen ab 65 in

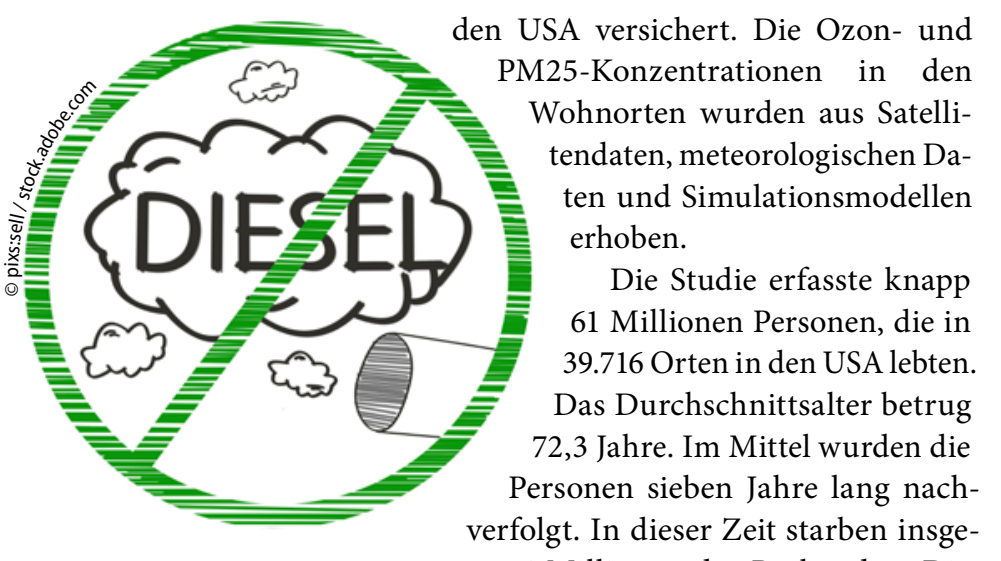
samt 22,6 Millionen der Probanden. Die PM25-Exposition an den Wohnorten lag zwischen 6,21 und $15,64 \mu \mathrm{g} / \mathrm{m}^{3}$, die Ozonkonzentration zwischen 36,27 und 55,86 ppb.

Die Auswertung ergab für eine Erhöhung der PM25-Exposition um $10 \mu \mathrm{g} / \mathrm{m}^{3}$ einen Zuwachs an Mortalität um 7,3\% (95\%-Konfidenzintervall: 7,1-7,5). Eine Steigerung der Ozonbelastung um $10 \mathrm{ppb}$ zog eine Erhöhung der Mortalität um 1,1\% (KI: 1,0-1,2) nach sich. Die Subgruppenanalysen zeigte einen größeren Effekt für Männer und für schwarze, hispanische und asiatische Bevölkerungsgruppen. Auch Personen mit niedrigem sozioökonomischem Status waren benachteiligt.

- Di Q, Wang Y, Zanobetti A et al. Air pollution and mortality in the Medicare population. N EnglJ Med. 2016;376:2513-22

\section{KOMMENTAR}

Es gibt einfach keine Konzentration an Feinstaub in der Luft, die gesundheitlich sicher unbedenklich ist. Diese große Studie zeigt eine dosisabhängige Mortalitätserhöhung für die Feinstaubbelastung. Sie drängt auf strengere gesetzliche Regelung und konterkariert die Absichten von US-Präsident Donald Trump, generell zu deregulieren.

\section{Hier steht eine Anzeige.}

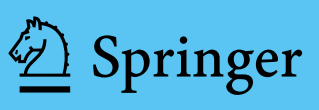

